\title{
PADRÃO DE QUALIDADE DE MUDAS DE Trema micrantha $($ L.) Blume, PRODUZIDAS SOB DIFERENTES PERÍODOS DE SOMBREAMENTO ${ }^{1}$
}

\author{
Ésio de Pádua Fonseca² ${ }^{2}$ Sérgio Valiengo Valéri ${ }^{3}$, Édison Miglioranza² ${ }^{2}$ Nilva Aparecida Nicolao Fonseca ${ }^{4}$ e \\ Laércio Couto ${ }^{5}$
}

\begin{abstract}
RESUMO - O objetivo deste trabalho foi verificar a influência do período de permanência das mudas sob sombreamento nos parâmetros empregados na avaliação da qualidade das mudas de Trema micrantha (crindiúva). O delineamento experimental foi o inteiramente casualizado, com quatro repetições por tratamento, contendo 88 plantas cada. Foram realizadas três avaliações, aos 90, 120 e 150 dias após a emergência. Os tratamentos na avaliação I foram 45, 60, 75 e 90; na avaliação II, 45, 60, 75, 90, 105 e 120; e na avaliação III, 45, 60, 75, 90, 105, 120, 135 e 150 dias de permanência sob sombreamento com 48\% de retenção da radiação, respectivamente. Foram avaliados os parâmetros morfológicos das mudas, suas relações e o índice de qualidade de Dickson. As mudas desenvolvidas sob maiores períodos de sombreamento, embora tenham alcançado maiores alturas das partes aéreas e áreas foliares, apresentaram as piores qualidades, com redução do diâmetro do coleto, da massa seca do sistema radicular e do índice de qualidade de Dickson e aumento da relação altura da parte aérea/diâmetro do coleto e da relação parte aérea/sistema radicular. Nas três avaliações, o período de permanência das mudas sob sombreamento não influenciou significativamente os parâmetros área foliar, massa seca das folhas, massa seca da parte aérea e massa seca total. As mudas apresentaram melhores padrões de qualidade e condições de plantio no campo a partir dos 120 dias de idade, quando crescidas sob 45 e 60 dias de sombreamento. $\mathrm{O}$ índice de qualidade de Dickson foi bom indicador do padrão de qualidade das mudas.
\end{abstract}

Palavras-chave: Sombreamento, viveiro, mudas, índice de qualidade, muda-padrão, padrão de qualidade de muda e crindiúva.

\section{TARGET SEEDLINGS OF Trema micrantha (L.) Blume GROWN UNDER DIFFERENT PERIODS OF SHADING}

\begin{abstract}
This work aimed to verify the influence of the under shading period in the parameters employed to evaluate Trema micrantha (crindiúva) seedling quality pattern. The research was carried out using a randomized design, with four replications per treatment and 88 plants per replication. Three evaluations were performed at 90, 120 and 150 days after emergence. The following treatments were used in the evaluation: Evaluation I, 45, 60, 75 and 90; Evaluation II, 45, 60, 75, 90, 105 and 120 and Evaluation III, 45, 60, 75, 90, 105, 120, 135 and 150 days under shading with $48 \%$ of solar radiation retention, respectively. The morphological parameters of the seedlings, their relationships, and the Dickson quality index were evaluated. Seedlings developed under the longer shading periods presented higher shoot heights and leaf area but the lowest values for seedling quality, such as smaller stem diameter, root dry mass and the Dickson quality index. They also presented an increase in shoot height/stem diameter and shoot/root ratios. Period under shading did not affect significantly the parameters for leaf area, leaf dry mass, shoot and total. Seedlings showed better quality patterns at 120 days, when grown under 45 and 60 days under shading. The Dickson's quality index was the best and the most suitable parameter to evaluate the target seedling grown in a suspended nursery.
\end{abstract}

Key words: $\quad$ Shading, nursery, seedling, quality index, target seedling, seedling quality pattern and crindiúva.

1 Recebido para publicação em 12.3.2001.

Aceito para publicação em 20.6.2002.

Parte da tese de doutorado em Agronomia do primeiro autor - bolsista da CAPES - FCAVJ-UNESP.

2 Professores do Departamento de Agronomia da UEL, <esiof@uel.br e emiglior@uel.br>. ${ }^{3}$ Professor do Departamento de Horticultura da FCAVJ-UNESP, <valeri@fcavj.unesp.br>. ${ }^{4}$ Professora do Departamento de Zootecnia da UEL, <nilva@uel.br>.

${ }^{5}$ Professor do Departamento de Engenharia Florestal da UFV, <lcouto@mail.ufv.br>. 


\section{INTRODUÇÃO}

Os programas de implantação, recomposição e revitalização de florestas nativas só terão sucesso garantido quando os métodos e sistemas empregados pelos viveiristas priorizarem a produção de mudas com qualidade e baixo custo.

Um dos principais problemas dos viveiros setorizados produtores de mudas de espécies florestais é determinar quais fatores, durante a fase de viveiro, alteram a sobrevivência e o desenvolvimento inicial das mudas no campo e quais as características da planta que se correlacionam melhor com essas variáveis. A obtenção de mudas de qualidade antes do plantio definitivo é importante para o silvicultor, e isto pode ser alcançado de maneira prática, rápida e fácil, observando-se parâmetros morfológicos. Os atributos das mudas, necessários para obtenção do sucesso do plantio no campo, têm sido denominados de "qualidade de muda". Segundo Duryea (1985), a qualidade pode ser definida como aqueles atributos necessários para que uma muda sobreviva e se desenvolva após o plantio no campo. Hunt (1990) recomendou o índice de qualidade de Dickson (IQD) como sendo bom indicador da qualidade de muda de Pseudotsuga menziesii (Mirb.) Franco e Picea abies L.

Segundo Parviainen (1981), a qualidade morfológica e fisiológica das mudas é função da qualidade da genética e da procedência das sementes, das condições ambientais do viveiro, dos métodos utilizados na produção das mudas, das estruturas e dos equipamentos utilizados no viveiro e do armazenamento e transporte das mudas.

As práticas de manejo de mudas podem alterar sua qualidade, e segundo Brissete et al. (1991) o sombreamento pode ser utilizado para auxiliar no controle excessivo de temperatura, particularmente no final da primavera e no verão, destacando que a redução da radiação solar, com telas, pode diminuir a temperatura dentro da casa de vegetação em até cinco graus Celsius.

Castro et al. (1996), estudando a espécie pioneira Muntingia calabura L., encontraram menores médias de massa seca total, diâmetros do coleto, altura e área foliar para mudas crescidas sob $100 \%$ da radiação fotossinteticamente ativa (RFA), quando comparadas com as crescidas sob 67 e $48 \%$. No entanto, as maiores taxas assimilatórias líquidas e massa seca das raízes foram obtidas nas plantas crescidas a $100 \%$ da RFA.
Segundo Lorenzi (2000), a Trema micrantha é uma espécie pioneira, de crescimento rápido, que produz anualmente grande quantidade de sementes, amplamente disseminadas por pássaros, e ocorre em todos os tipos de ambientes, exceto nos muito úmidos, o que explica sua vasta dispersão.

O objetivo do presente trabalho foi verificar a influência do período de permanência das mudas sob sombreamento/sol nos parâmetros empregados na avaliação da qualidade das mudas de Trema micrantha (L.) Blume (crindiúva).

\section{MATERIAL E MÉTODOS}

O experimento foi realizado em viveiro suspenso, tipo setorizado, localizado nas coordenadas $23^{\circ} 23^{\prime}$ de latitude sul e $51^{\circ} 11^{\prime}$ longitude oeste, altitude média de $566 \mathrm{~m}$ e clima do tipo Cfa, segundo Köppen, com precipitação média anual de $1.615 \mathrm{~mm}$.

O viveiro possui três setores distintos: 1 - setor de semeadura e germinação, que é protegido com plástico transparente e tela de polietileno de coloração preta, com retenção de $48 \%$ do fluxo da radiação solar, e provido de sistema de irrigação suspenso com microaspersores com vazão de $751 \mathrm{~h}^{-1} ; 2$ - setor de crescimento, coberto com tela de polietileno de coloração preta, com retenção de $48 \%$ do fluxo da radiação solar, e provido de sistema de irrigação semelhante ao do setor de germinação; e 3- setor de aclimatação ou rustificação das mudas, sem cobertura, com as mudas expostas a pleno sol e sistema de irrigação com microaspersores com vazão de $2701 \mathrm{~h}^{-1}$.

As sementes foram coletadas de 12 matrizes, nãoaparentadas. Foi efetuada a quebra de dormência das sementes, utilizando ácido sulfúrico concentrado, conforme recomendação de Castellani (1996). A semeadura ocorreu no dia 10 de agosto de 1998, logo após a coleta das sementes. Conforme o poder germinativo, cada recipiente recebeu de três a cinco sementes, visando garantir pelo menos uma planta por recipiente. No setor de germinação, a temperatura foi mantida em torno de $25^{\circ} \mathrm{C}$, com o auxílio da nebulização e com a abertura e o fechamento das cortinas laterais.

Utilizaram-se tubetes (tubo cônico de plástico rígido) com $50 \mathrm{~cm}^{3}$ volume, e o substrato foi preparado misturando-se vermicomposto, proveniente de esterco bovino e casca de arroz carbonizado, numa proporção de 8:2 em v/v (Quadro 1). Foram aplicados 2,0 kg de 
sulfato de amônio, $5,0 \mathrm{~kg}$ de superfosfato simples e $0,4 \mathrm{~kg}$ de cloreto de potássio por metro cúbico de substrato.

Após a completa emergência das plântulas, foi realizado o desbaste, deixando-se uma plântula por tubete. Em função da desuniformidade de emergência, as plântulas foram classificadas e padronizadas antes da definição e distribuição nos tratamentos, deixando-se apenas as plântulas com mínimo de um ou dois pares de folhas formadas.

Por ocasião da transferência das mudas do setor de germinação para o setor de crescimento, aos 25 dias após a semeadura, efetuou-se a alternagem dos recipientes, passando da lotação de 100 para $50 \%$ de cada bandeja, aumentando-se o espaçamento entre recipientes, a fim de reduzir a competição por luz e aumentar a aeração entre as mudas. A cada dez dias foram realizadas adubações de cobertura, aplicando manualmente 101 da solução que continha 7,04 g de nitrogênio $(\mathrm{N}), 14,08 \mathrm{~g}$ de $\mathrm{P}_{2} \mathrm{O}_{5} \mathrm{e}$ 7,04 g de $\mathrm{K}_{2} \mathrm{O}$, em $3,68 \mathrm{~m}^{2}$ de canteiro, equivalente a $0,0025 \mathrm{~g}$ de $\mathrm{N}, 0,005 \mathrm{~g}$ de $\mathrm{P}_{2} \mathrm{O}_{5}$ e $0,0025 \mathrm{~g}$ de $\mathrm{K}_{2} \mathrm{O}$ por muda.

Conforme a temperatura e umidade do ambiente, as mudas foram irrigadas duas a três vezes ao dia, no setor de sombreamento, e três a quatro vezes, no setor descoberto (pleno sol).
Foi adotado o delineamento inteiramente casualizado, por ocasião da alternagem, com quatro repetições por tratamento. Cada repetição correspondeu a uma bandeja com 88 mudas, dispostas na forma retangular (8 x 11). As avaliações foram efetuadas aos $90,120 \mathrm{e}$ 150 dias após a emergência das plântulas. Em cada uma dessas avaliações, as mudas permaneceram por diferentes períodos sob sombreamento e a pleno sol. A partir dos 45 dias após a emergência no setor de sombreamento, iniciou-se a retirada das mudas para o setor a pleno sol, com intervalos de 15 dias. No momento da primeira, segunda e terceira avaliação foram analisados quatro, seis e oito tratamentos, respectivamente. A descrição dos tratamentos e os períodos de avaliação estão apresentados no Quadro 2.

Foram avaliados o diâmetro do coleto (D), a altura da parte aérea (APA), o número de folhas (NF); a área foliar (AF), estimada com o uso do aparelho LI-Cor Mod. 3000; a massa seca das folhas (MSF), do caule (MSC), do sistema radicular (MSR); a massa seca da parte aérea (MSPA), obtida pela soma da MSF e MSC; a massa seca total (MST), obtida pela soma do MSPA e MSR; a relação da parte aérea/sistema radicular (RPAR), obtida da relação entre MSPA e MSR; e a relação da altura da parte aérea/diâmetro do coleto (RAD), obtida da relação entre APA e D e índice de qualidade de Dickson (IQD),

Quadro 1 - Características químicas do substrato (80\% de vermicomposto de esterco bovino + 20\% casca de arroz carbonizada, v/v)

Table 1 - Chemical characteristics of the substratum (80\% of cattle manure humus $+20 \%$ of carbonized rice husk, $v / v$ )

\begin{tabular}{|c|c|c|c|}
\hline Características & Teor & Características & Teor \\
\hline $\mathrm{PH} \mathrm{CaCl}{ }_{2}$ & 6,50 & Nitrogênio Total $\left(\mathrm{N}_{\mathrm{T}}\right) \mathrm{g} / \mathrm{dm}^{3}$ & 5,50 \\
\hline $\mathrm{H}+\mathrm{Al} \mathrm{cmol} / \mathrm{dm}^{3}$ & 2,26 & Cálcio $\left(\mathrm{Ca}^{+2}\right) \mathrm{cmol}_{\mathrm{c}} / \mathrm{dm}^{3}$ & 9,98 \\
\hline Acidez Total $\left(\mathrm{H}^{+}\right) \mathrm{cmol}_{\mathrm{C}} / \mathrm{dm}^{3}$ & 2,26 & Magnésio $\left(\mathrm{Mg}^{+2}\right) \mathrm{cmol}_{\mathrm{c}} / \mathrm{dm}^{3}$ & 8,65 \\
\hline Alumínio $\left(\mathrm{Al}^{+3}\right) \mathrm{cmol}_{\mathrm{c}} / \mathrm{dm}^{3}$ & 0,00 & Potássio $\left(\mathrm{K}^{+}\right) \mathrm{cmol}_{\mathrm{c}} / \mathrm{dm}^{3}$ & 4,35 \\
\hline Matéria Orgânica (MO) g/dm ${ }^{3}$ & 110,07 & Fósforo $(\mathrm{P}) \mathrm{mg} / \mathrm{dm}^{3}$ & 194,71 \\
\hline CTC $\left(\mathrm{pH} \mathrm{7,0)} \mathrm{cmol}_{\mathrm{c}} / \mathrm{dm}^{3}\right.$ & 25,25 & Saturação (V \%) \% & 91,03 \\
\hline CTC (Efetiva) $\mathrm{cmol}_{\mathrm{c}} / \mathrm{dm}^{3}$ & 22,98 & Enxofre $\left(\mathrm{SO}_{4}{ }^{-2}\right) \mathrm{mg} / \mathrm{dm}^{3}$ & 17,14 \\
\hline Saturação (V\%) \% & 91,03 & & \\
\hline \multicolumn{3}{|c|}{ Micronutrientes } & Teor \\
\hline \multicolumn{3}{|l|}{ Manganês (Mn) mg/dm ${ }^{3}$} & 369,80 \\
\hline \multicolumn{3}{|l|}{ Ferro $(\mathrm{Fe}) \mathrm{mg} / \mathrm{dm}^{3}$} & 192,30 \\
\hline \multicolumn{3}{|l|}{ Cobre $(\mathrm{Cu}) \mathrm{mg} / \mathrm{dm}^{3}$} & 7,01 \\
\hline \multicolumn{3}{|l|}{ Zinco $(\mathrm{Zn}) \mathrm{mg} / \mathrm{dm}^{3}$} & 35,80 \\
\hline \multicolumn{3}{|l|}{ Boro $(B) \mathrm{mg} / \mathrm{dm}^{3}$} & 0,47 \\
\hline
\end{tabular}

Extratores- $\left(\mathrm{P}, \mathrm{K}^{+}\right)=$Mehlich-1; $\left(\mathrm{Ca}^{+2}, \mathrm{Mg}^{+2}, \mathrm{AL}^{+3}\right)=\mathrm{KCl} 1 \mathrm{~N}$ e $(\mathrm{Mn}, \mathrm{Fe}, \mathrm{Cu}, \mathrm{Zn})=$ Mehlich-1 e $(\mathrm{B})=\mathrm{HCl} 0,05 \mathrm{~N}$. 
Quadro 2 - Caracterização dos tratamentos em função do período de permanência das mudas sob sombreamento (sombra) e a pleno sol (sol), aos 90, 120 e 150 dias após a emergência

Table 2 - Characterization of the treatments in function of the period of permanence of the seedlings under shading (shade) and full sun (sun), at 90, 120 and 150 days after emergence

\begin{tabular}{|c|c|c|c|c|c|c|}
\hline \multirow{3}{*}{$\begin{array}{c}\text { Trata- } \\
\text { mento }\end{array}$} & \multicolumn{6}{|c|}{ Dias Após a Emergência } \\
\cline { 2 - 7 } & $\begin{array}{c}\text { Sombra } \\
\text { (dias) }\end{array}$ & $\begin{array}{c}\text { Sol } \\
\text { (dias) }\end{array}$ & $\begin{array}{c}\text { Sombra } \\
\text { (dias) }\end{array}$ & $\begin{array}{c}\text { Sol } \\
\text { (dias) }\end{array}$ & $\begin{array}{c}\text { Sombra } \\
\text { (dias) }\end{array}$ & $\begin{array}{c}\text { Sol } \\
\text { (dias) }\end{array}$ \\
\hline 1 & 45 & 45 & 45 & 75 & 45 & 105 \\
2 & 60 & 35 & 60 & 60 & 60 & 90 \\
3 & 75 & 15 & 75 & 45 & 75 & 75 \\
4 & 90 & 0 & 90 & 30 & 90 & 60 \\
5 & & & 105 & 15 & 105 & 45 \\
6 & & & 120 & 0 & 120 & 30 \\
7 & & & & & 135 & 15 \\
8 & & & & & 150 & 0 \\
\hline
\end{tabular}

segundo Dickson et al. (1960), em que IQD= MST/ (RAD+RPAR). Em cada um dos três períodos de avaliação utilizaram-se três mudas retiradas ao acaso, para cada repetição, para determinação dos parâmetros morfológicos, das relações e dos índices utilizados. Após as retiradas e a destruição das mudas utilizadas em cada avaliação, as remanescentes foram rearranjadas na bandeja, para manter o mesmo espaçamento entre elas.

Os componentes folha, caule e raiz foram secos em estufa de circulação forçada a $75^{\circ} \mathrm{C}$, até atingir o peso constante.

Foram feitas análises de regressão para todos os parâmetros estudados, em função dos períodos de permanência das mudas sob sombreamento, para as três avaliações realizadas.

\section{RESULTADOS E DISCUSSÃO}

No Quadro 3 estão apresentados as médias dos parâmetros morfológicos, as relações e o índice empregado para avaliação da qualidade de mudas de crindiúva, obtidas nas avaliações realizadas aos 90, 120 e 150 dias após a emergência.

No Quadro 4 e na Figura 1, observa-se que ocorreu decréscimo linear do diâmetro do coleto em função do aumento do período de permanência sob sombreamento, nas três avaliações. Segundo Kozlowski (1962), o aumento do sombreamento diminui a fotossíntese e, conseqüentemente, a quantidade de fotoassimilados e reguladores de crescimento, causando redução do diâmetro do coleto. $\mathrm{O}$ autor considera ainda que a fotossíntese, aparentemente, guarda uma relação mais direta com o crescimento em diâmetro do que em altura. Autores como Boyer e South (1984) também encontraram influência do sombreamento no desenvolvimento do diâmetro do coleto e observaram que mudas de Pinus taeda L. crescidas em condições de casa de vegetação tiveram maior altura da parte aérea e foram mais delgadas e menos ramificadas do que as crescidas a pleno sol. Destacaram ainda que essas diferenças morfológicas, aparentemente, foram causadas pela mudança do comprimento de onda da luz e pela proteção contra o vento.

A altura da parte aérea, nas três avaliações, elevouse linearmente com o aumento do período de permanência das mudas sob sombreamento. Resultados semelhantes foram observados por Ferreira et al. (1977), em mudas de Enterolobium contortisiliquum (Vell.) Morong, e por Fleming et al. (1985), Muntingia calabura L.

O período de permanência sob sombreamento afetou significativamente o número de folhas das mudas apenas na avaliação realizada aos 120 dias, apresentando efeito quadrático (Figura 1 e Quadro 4), com ponto mínimo aos 83 dias de sombreamento.

A área foliar elevou-se linearmente com o aumento do período de permanência sob sombreamento, para os três períodos de avaliação. Segundo Benincasa (1988), esse aumento pode ser explicado pelo auto-sombreamento, que a partir de um determinado limite passa a ser prejudicial, porque promove o aumento do número de folhas ou da superfície foliar, diminuindo bastante sua eficiência fotossintética e a evapotranspiração.

Não foi observado efeito do período de permanência sob sombreamento na massa seca das folhas, massa seca da parte aérea e total, nas três avaliações. Mas, para a massa seca do caule, houve efeito linear decrescente em função do aumento do período de permanência sob sombreamento, na avaliação realizada aos 150 dias (Figura 1).

A massa seca das folhas não acompanhou, proporcionalmente, as variações de crescimento em área foliar, o que pode ser explicado pelo fato de a luz favorecer o desenvolvimento nas folhas de células empaliçadas longas e cutícula mais espessa, enquanto o sombreamento favorece a produção de maior quantidade de parênquima lacunoso (Taiz \& Zeiger, 1991), aumentando o tamanho da folha e diminuindo a densidade específica. 
Quadro 3 - Avaliação do D, APA, NF, AF, MSF, MSC, MSPA, MSR, MST, RPAR, RAD e IQD das mudas de T. micrantha (L.) Blume, cultivadas em diferentes períodos sob sombreamento, aos 90,120 e 150 dias após a emergência

Table 3 - Evaluation of D, APA, NF, AF, MSF, MSC, MSPA, MSR, MST, RPAR, RAD and IQD in seedlings of T. micrantha (L.) Blume, grown under diferent periods of shading at 90, 120 and 150 days after emergence

\begin{tabular}{|c|c|c|c|c|c|c|c|c|c|c|c|c|c|}
\hline Dias & $\begin{array}{c}\text { Som- } \\
\text { breamento } \\
\text { (dias) }\end{array}$ & $\begin{array}{c}\mathrm{D} \\
(\mathrm{mm})\end{array}$ & $\begin{array}{l}\text { APA } \\
(\mathrm{cm})\end{array}$ & $\mathrm{NF}$ & $\begin{array}{c}\mathrm{AF} \\
\left(\mathrm{cm}^{2}\right)\end{array}$ & $\begin{array}{l}\text { MSF } \\
(\mathrm{g})\end{array}$ & $\begin{array}{c}\text { MSC } \\
(\mathrm{g})\end{array}$ & $\begin{array}{c}\text { MSPA } \\
(\mathrm{g})\end{array}$ & $\begin{array}{c}\text { MSR } \\
(\mathrm{g})\end{array}$ & $\begin{array}{c}\text { MST } \\
(\mathrm{g})\end{array}$ & RPAR & RAD & IQD \\
\hline \multirow{6}{*}{90} & 45 & 2,71 & 16,91 & 8,58 & 87,72 & 0,5942 & 0,2608 & 0,8550 & 0,4667 & 1,3217 & 1,97 & 6,24 & 0,1617 \\
\hline & 60 & 2,65 & 17,12 & 8,92 & 88,17 & 0,5858 & 0,2383 & 0,8242 & 0,4075 & 1,2317 & 2,07 & 6,50 & 0,1450 \\
\hline & 75 & 2,43 & 19,71 & 8,50 & 96,62 & 0,5800 & 0,2375 & 0,8175 & 0,3533 & 1,1708 & 2,57 & 8,49 & 0,1167 \\
\hline & 90 & 2,42 & 21,02 & 9,00 & 107,14 & 0,5817 & 0,2083 & 0,7900 & 0,3508 & 1,1408 & 2,44 & 8,83 & 0,1050 \\
\hline & Média & 2,55 & 18,69 & 8,75 & 94,91 & 0,5854 & 0,2362 & 0,8217 & 0,3946 & 1,2262 & 2,26 & 7,51 & 0,1321 \\
\hline & $\mathrm{CV}(\%)$ & 15,22 & 13,53 & 22,78 & 22,38 & 24,71 & 28,92 & 23,20 & 30,27 & 20,97 & 34,33 & 19,01 & 29,24 \\
\hline \multirow{8}{*}{120} & 45 & 3,21 & 21,79 & 8,58 & 104,34 & 0,7017 & 0,4892 & 1,1908 & 0,6208 & 1,8117 & 1,96 & 6,85 & 0,2083 \\
\hline & 60 & 3,24 & 22,11 & 7,83 & 102,76 & 0,6908 & 0,4683 & 1,1592 & 0,6242 & 1,7833 & 1,94 & 6,84 & 0,2058 \\
\hline & 75 & 3,19 & 23,42 & 7,92 & 121,20 & 0,7192 & 0,4567 & 1,1758 & 0,6100 & 1,7858 & 2,06 & 7,42 & 0,1950 \\
\hline & 90 & 3,13 & 26,33 & 7,67 & 122,13 & 0,6708 & 0,4808 & 1,1517 & 0,5675 & 1,7192 & 2,16 & 8,42 & 0,1658 \\
\hline & 105 & 2,92 & 27,40 & 7,58 & 117,43 & 0,6425 & 0,4500 & 1,0925 & 0,5058 & 1,5983 & 2,25 & 9,45 & 0,1383 \\
\hline & 120 & 2,97 & 28,60 & 8,83 & 140,21 & 0,6933 & 0,4767 & 1,1700 & 0,5058 & 1,6758 & 2,41 & 9,69 & 0,1400 \\
\hline & Média & 3,11 & 24,94 & 8,07 & 118,01 & 0,6864 & 0,4703 & 1,1567 & 0,5724 & 1,7291 & 2,13 & 8,11 & 0,1755 \\
\hline & $\mathrm{CV}(\%)$ & 9,66 & 12,65 & 16,48 & 17,54 & 20,15 & 22,32 & 17,01 & 24,31 & 15,87 & 27,07 & 14,47 & 21,95 \\
\hline \multirow{10}{*}{150} & 45 & 3,83 & 31,04 & 9,25 & 60,50 & 0,5308 & 1,0058 & 1,5367 & 0,8542 & 2,3908 & 1,82 & 8,15 & 0,2425 \\
\hline & 60 & 3,57 & 30,38 & 8,08 & 62,08 & 0,4892 & 0,8767 & 1,3658 & 0,6692 & 2,0351 & 2,13 & 8,58 & 0,1933 \\
\hline & 75 & 3,46 & 30,18 & 7,25 & 68,56 & 0,6042 & 0,8092 & 1,4133 & 0,6133 & 2,0267 & 2,37 & 8,96 & 0,1875 \\
\hline & 90 & 3,47 & 32,24 & 6,83 & 67,09 & 0,5375 & 0,8550 & 1,3925 & 0,6233 & 2,0158 & 2,43 & 9,36 & 0,1717 \\
\hline & 105 & 3,34 & 33,27 & 7,83 & 81,25 & 0,6567 & 0,8808 & 1,5375 & 0,5625 & 2,1000 & 2,88 & 9,96 & 0,1667 \\
\hline & 120 & 3,27 & 32,12 & 7,50 & 86,73 & 0,6308 & 0,7692 & 1,4000 & 0,5842 & 1,9842 & 2,54 & 9,92 & 0,1650 \\
\hline & 135 & 3,13 & 32,54 & 8,17 & 93,71 & 0,6467 & 0,8517 & 1,4983 & 0,5567 & 2,0551 & 2,85 & 10,47 & 0,1558 \\
\hline & 150 & 3,14 & 32,96 & 7,58 & 102,77 & 0,6517 & 0,7667 & 1,4183 & 0,5567 & 1,9751 & 2,57 & 10,51 & 0,1492 \\
\hline & Média & 3,40 & 31,84 & 7,81 & 77,84 & 0,5934 & 0,8519 & 1,4453 & 0,6275 & 2,0728 & 2,45 & 9,49 & 0,1790 \\
\hline & CV $(\%)$ & 11,73 & 9,79 & 32,01 & 24,81 & 30,03 & 23,74 & 20,48 & 24,93 & 18,31 & 27,32 & 11,45 & 24,05 \\
\hline
\end{tabular}

Para as avaliações aos 90 e 120 dias, a massa seca do sistema radicular foi reduzida linearmente de maneira significativa, em função do aumento do período sob sombreamento. Entretanto, aos 150 dias foi observado efeito quadrático, com ponto mínimo aos 124 dias (Quadro 4 e Figura 2). A redução da massa seca do sistema radicular com o aumento do período sob sombreamento, segundo Bongarten e Teskey (1987), deve-se ao fato de as mudas crescidas a pleno sol estarem sujeitas à maior restrição hídrica, que pode induzir ao crescimento da massa seca do sistema radicular em detrimento do acúmulo de assimilados na parte aérea, como ocorrido com Pinus taeda L.

Nas três avaliações, observa-se que o sistema radicular foi um dos componentes da muda que mais respondeu ao aumento do período sob sombreamento durante a fase de aclimatação, diminuindo a massa seca do sistema radicular.

Para a relação parte aérea/sistema radicular aos 90 dias, não ocorreram diferenças entre os períodos de sombreamento. A ausência de diferença significativa indica que as mudas apresentaram o mesmo padrão de distribuição de matéria seca entre os dois órgãos, independentemente do período de permanência sob sombreamento. Por outro lado, o maior acúmulo de massa seca da parte aérea pode ser explicado, em parte, pelo pequeno porte e volume do recipiente, o que pode restringir a disponibilidade de água e de nutriente e a expansão do sistema radicular. Aos 120 e 150 dias foram observados efeitos lineares crescente e quadrático, respectivamente, em função do aumento do período sob sombreamento. 
Quadro 4 - Equações de regressão dos parâmetros estudados em mudas de T. micrantha (L.) Blume, em função dos períodos de permanência sob sombreamento

Table 4 - Equations of regression of the parameters studied in seedlings of T. micrantha (L.) Blume, in function of the periods under shading

\begin{tabular}{|c|c|c|c|c|}
\hline Avaliação & Característica & Equações de Regressão & $\mathrm{F}$ & $\overline{\mathrm{R}^{2}}$ \\
\hline \multirow{12}{*}{$\begin{array}{c}\text { Aos } \\
90 \text { dias }\end{array}$} & $\mathrm{D}$ & $Y=3,04333-0,00727778 X$ & $*$ & 0,90 \\
\hline & APA & $Y=11,9808+0,0993889 X$ & $*$ & 0,92 \\
\hline & $\mathrm{NF}$ & NS & & \\
\hline & $\mathrm{AF}$ & $Y=64,9022+0,444594 X$ & $*$ & 0,89 \\
\hline & MSF & NS & & \\
\hline & MSC & NS & & \\
\hline & MSPA & NS & & \\
\hline & MSR & $Y=0,575333-0,00267778 X$ & $*$ & 0,90 \\
\hline & MST & NS & & \\
\hline & RPAR & NS & & \\
\hline & RAD & $\mathrm{Y}=3,1285+0,0649667 \mathrm{X}$ & $* *$ & 0,89 \\
\hline & IQD & $Y=0,221333-0,00132222 X$ & $* *$ & 0,98 \\
\hline \multirow{12}{*}{$\begin{array}{c}\text { Aos } \\
120 \text { dias }\end{array}$} & $\mathrm{D}$ & $Y=3,45944-0,00422222 X$ & $* *$ & 0,79 \\
\hline & APA & $Y=16,6393+0,100635 X$ & $* *$ & 0,96 \\
\hline & $\mathrm{NF}$ & $Y=12,5856-0,122742 X+0,000740716 X^{2}$ & $*$ & 0,78 \\
\hline & $\mathrm{AF}$ & $Y=82,7677+0,427200 X$ & $* *$ & 0,76 \\
\hline & MSF & NS & & \\
\hline & MSC & NS & & \\
\hline & MSPA & NS & & \\
\hline & MSR & $Y=0,725183-0,00185238 X$ & $* *$ & 0,88 \\
\hline & MST & NS & & \\
\hline & RPAR & $Y=1,61148+0,00629682 X$ & $*$ & 0,95 \\
\hline & RAD & $Y=4,49265+0,0438635 X$ & $* *$ & 0,94 \\
\hline & IQD & $Y=0,265651-0,00109206 X$ & $* *$ & 0,92 \\
\hline \multirow{12}{*}{$\begin{array}{c}\text { Aos } \\
150 \text { dias }\end{array}$} & $\mathrm{D}$ & $\mathrm{Y}=3,99663-0,00609788 \mathrm{X}$ & $* *$ & 0,92 \\
\hline & APA & $Y=29,4403+0,0246296 X$ & $* *$ & 0,60 \\
\hline & $\mathrm{NF}$ & NS & & \\
\hline & $\mathrm{AF}$ & $Y=37,3913+0,414819 X$ & $* *$ & 0,95 \\
\hline & MSF & NS & & \\
\hline & MSC & $Y=0,998383-0,00150265 X$ & $*$ & 0,51 \\
\hline & MSPA & NS & & \\
\hline & MSR & $Y=1,19159-0,0103669 X+0,0000417949 X^{2}$ & $* *$ & 0,89 \\
\hline & MST & NS & & \\
\hline & RPAR & $Y=0,467854+0,0363794 X-0,000146593 X^{2}$ & $*$ & 0,85 \\
\hline & RAD & $Y=7,21463+0,0233029 X$ & $* *$ & 0,97 \\
\hline & IQD & $Y=0,324873-0,00248725 X+0,00000903784 X^{2}$ & $*$ & 0,91 \\
\hline
\end{tabular}

$\mathrm{X}=$ períodos de permanência das mudas sob sombreamento.

$\mathrm{F}=$ nível de significância da regressão, em que ** $(\mathrm{P}<0,01)$ e $*(\mathrm{P}<0,05)$.

$\mathrm{R}^{2}=$ coeficiente de determinação. 

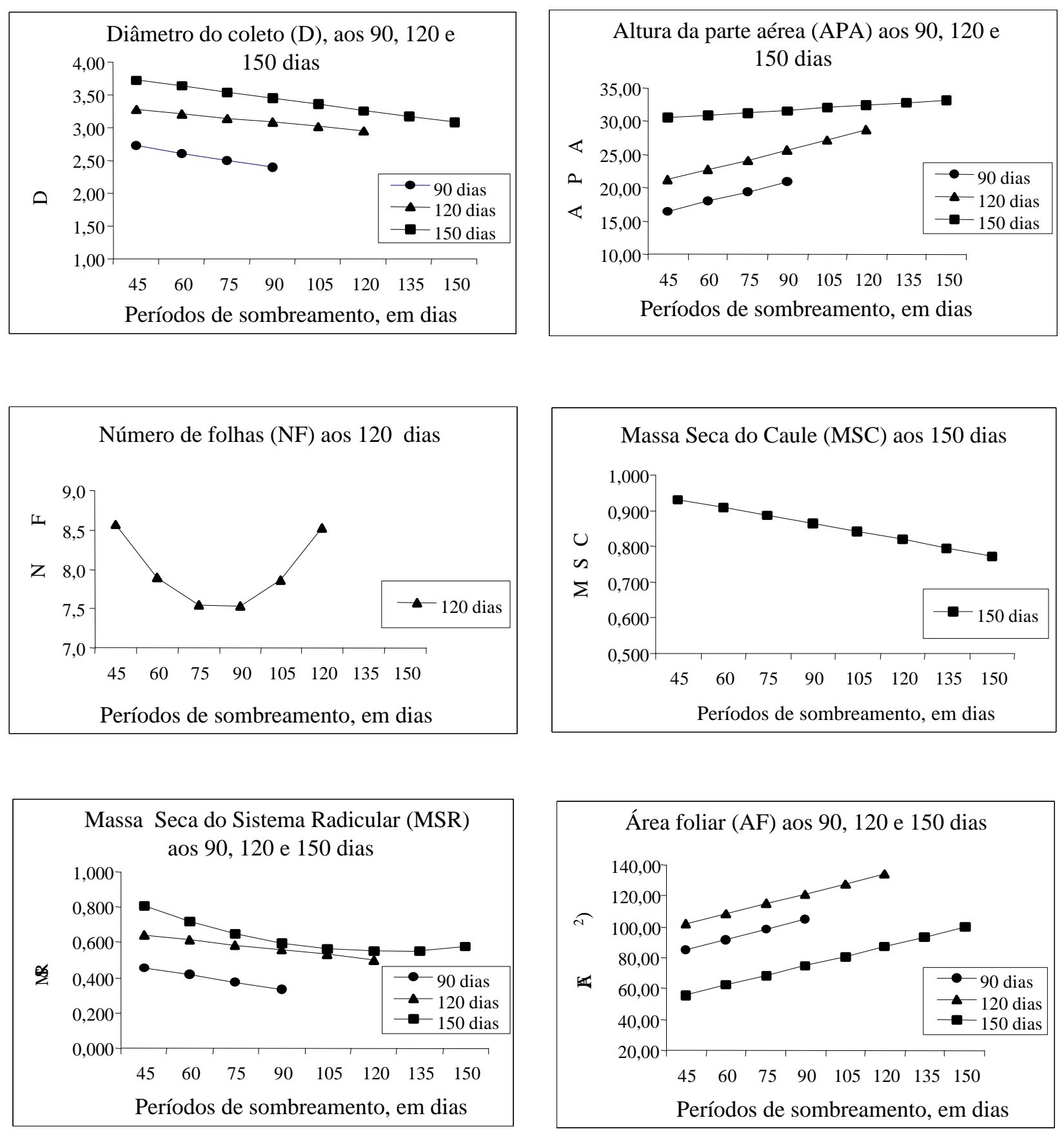

Figura 1 - Variação do D, APA, NF, AF, MSC e MSR das mudas de T. micrantha (L.) Blume, em função dos períodos de permanência sob sombreamento, aos 90,120 e 150 dias após emergência.

Figure 1 -Variation of D, APA, NF, AF, MSC and MSR in seedlings of T. micrantha (L.) Blume, in function of the periods under shading, at 90,120 and 150 days after emergence. 

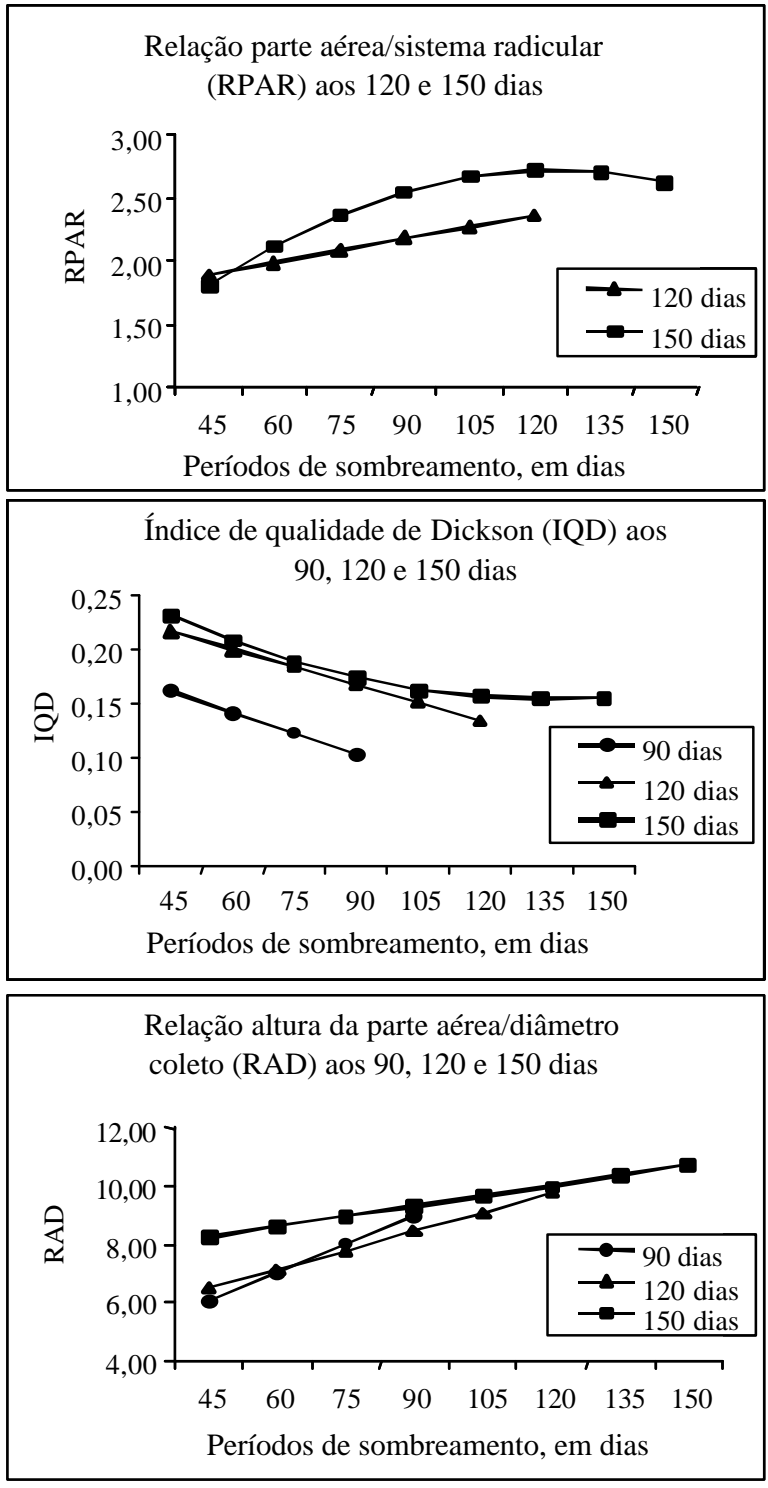

Figura 2 - Variação do RPAR, RAD e IQD das mudas de T micrantha (L.) Blume, em função dos períodos de permanência sob sombreamento, aos 90,120 e 150 dias após emergência.

Figure 2-Variation of RPAR, RAD and IQD in seedlings of T. micrantha (L.) Blume, in function of the periods under shading, at 90, 120 and 150 days after emergence.

Segundo Lavender (1984), as plantas crescidas com maior disponibilidade de água e nutriente, ou ambos, em local sombreado, têm maior taxa de parte aérea/raiz em relação às plantas crescidas com relativo défice hídrico e de nutrientes a pleno sol.

R. Árvore, Viçosa-MG, v.26, n.4, p.515-523, 2002
De modo geral, as mudas apresentaram aumento linear significativo da relação altura da parte aérea/diâmetro do coleto com o aumento do período sob sombreamento, explicado pelo incremento da altura da parte aérea e redução do diâmetro do coleto. Aos 90 e aos 120 dias, as mudas crescidas com 45 e 60 dias e com 45, 60 e 75 dias sob sombreamento, respectivamente, apresentaram valores da relação da altura da parte aérea/diâmetro do coleto (inferior a 8) semelhantes àqueles recomendados por Mitchel et al., citados por Hunt (1990), e por Carneiro (1995) (Quadro 3). Desta forma, a relação altura da parte aérea/diâmetro do coleto deve ser utilizada em conjunto com outros parâmetros na determinação do melhor padrão de qualidade das mudas.

Ocorreu comportamento linear decrescente do índice de qualidade de Dickson em função do aumento do período sob sombreamento, para avaliações aos 90 e 120 dias, e quadrático (ponto mínimo aos 138 dias), para avaliação aos 150 dias após a emergência. As mudas com maiores índices de qualidade de Dickson apresentaram maiores valores de diâmetro do coleto, massa seca da parte aérea, do sistema radicular e total, e menores valores da relação parte aérea/sistema radicular e da relação altura da parte aérea/diâmetro do coleto.

Estabelecendo como padrão o valor mínimo do índice de qualidade de Dickson em 0,20 para as mudas produzidas em recipientes de 50 ou $60 \mathrm{ml}$, como recomendado por Hunt (1990), observa-se que as mudas somente atingiram esse valor a partir dos 120 dias após a emergência, com 45 e 60 dias sob sombreamento (Figura 2), indicando que apresentam qualidade para serem plantadas no campo.

Os parâmetros morfológicos e as relações utilizadas para avaliação da qualidade das mudas não devem ser utilizados isoladamente para classificação do padrão da qualidade de mudas, a fim de que não corra o risco de selecionar mudas mais altas, porém fracas, descartando as menores, mas com maior vigor.

O índice de qualidade de Dickson é um bom indicador da qualidade das mudas, pois no seu cálculo são considerados a robustez e o equilíbrio da distribuição da biomassa na muda, ponderando os resultados de vários parâmetros importantes empregados para avaliação da qualidade.

\section{CONCLUSÕES}

A qualidade das mudas foi afetada pelo período de permanência sob sombreamento, alterando alguns 
parâmetros morfológicos, as relações e o índice utilizado na avaliação.

As mudas desenvolvidas sob maiores períodos de sombreamento, embora tenham alcançado maiores alturas das partes aéreas e áreas foliares, foram as que apresentaram os piores valores para avaliação da qualidade de mudas, como menores valores de diâmetro de coleto, massa seca do sistema radicular e do índice qualidade de Dickson, e aumento das relações altura da parte aérea/ diâmetro do coleto e da parte aérea/sistema radicular.

O sistema radicular das mudas foi o componente que sofreu os piores efeitos em função do aumento do período de sombreamento.

As mudas apresentaram padrões de qualidade adequados para o plantio definitivo, a partir dos 120 dias após emergência, quando crescidas sob 45 e 60 dias de sombreamento.

O índice de qualidade de Dickson foi bom parâmetro para indicar o padrão de qualidade das mudas crescidas nas condições de viveiro suspenso.

\section{REFERÊNCIAS BIBLIOGRÁFICAS}

BENINCASA, M. M. P. Análise de crescimento de plantas (Noções básicas). Jaboticabal: FUNEP, 1988. $41 \mathrm{p}$.

BONGARTEN, B. C.; TESKEY, R. O. Dry weight partitioning and its relationships to productivity in loblolly pine seedling from seven sources. Forest Science, v. 33, n. 3, p. 255-267, 1987.

BOYER, J.; SOUTH, D. A morphological comparison of greenhouse-grown loblolly pine seedlings with seedlings grown outdoors. Tree Planter's Notes, v. 16, p. 15-18, 1984.

BRISSETE, J. C.; BARNETT, T. J.; LANDIS, T. D. Container Seedlings. In: DURYEA, M.L., DOUGHERTY, P.M. (Eds) Forest regeneration manual, Dordrecht: Kluwer Academic Publishers, 1991. p. 117-41.

CARNEIRO, J. G. A. Produção e controle de qualidade de mudas florestais. Viçosa: Folha de Viçosa, 1995. p. 63-95.

CASTELLANI, E. D. Caracterização e germinação de sementes de Trema micrantha (L.) Blume. Jaboticabal: Universidade Estadual de São Paulo, 1996. 124 p. Dissertação (Mestrado em Agronomia) - Universidade Estadual de São Paulo, 1996.
CASTRO, E. M.; ALVARENGA, A. A.; GOMIDE, M. B. Crescimento e distribuição de matéria seca de mudas de calabura (Muntingia calabura L.) submetidas a três níveis de irradiância. Ciência e Agrotécnica, v. 20, n. 3, p. $357-$ $365,1996$.

DICKSON, A.; LEAF, A. L.; HOSNER, J. F. Quality appraisal of white spruce and white pine seedling stock in nurseries. Forestry Chronicle, v. 36, p. 10-13, 1960.

DURYEA, M. L. Evaluating seedling quality importance to reforestation. In: DURYEA, M. L. Evaluating seedling quality principles, procedures, and predictive abilities of major tests. Corvallis: Forest Research Laboratory Oregon State University, 1985. p. 1-6.

FERREIRA, M. G. M.; CÂNDIDO, J. F.; CANO, M. A. O. Efeito do sombreamento na produção de mudas de quatro espécies florestais nativas. Revista Árvore, v. 1, n. 2, p. 121-34, 1977.

FLEMING, T. H. et al. Phenology seed dispersal, and colonization in Muntingia calabura L., a neotropical pionneer tree. American Journal of Botany, v. 72, n. 3, p. 383-391, 1985.

HUNT, G. A. Effect of styroblock design and cooper treatment on morphology of conifer seedlings. In: TARGET SEEDLING SYMPOSIUM, MEETING OF THE WESTERN FOREST NURSERY ASSOCIATIONS, GENERAL TECHNICAL REPORT RM-200, 1990, Roseburg. Proceedings... Fort Collins: United States Departament of Agriculture, Forest Service, 1990. p. $218-222$.

KOZLOWSKI, T. T. Tree growth. New York: The Ronald Press, 1962. p. 149-170.

LAVENDER, D. P. Plant physiology and nursery environment: interactions affecting seedling growth. In: DURYEA, M. L.; THOMAS, D.L. Forest nursery manual: production of bareroot seedlings. Corvallis: Oregon State University, 1984. p. 133-141.

LORENZI, H. Árvores Brasileiras: manual de identificação e cultivo de plantas arbóreas do Brasil. 3.ed. Nova Odessa: Instituto Plantarum, 2000. 373 p.

PARVIAINEN, J. V. Qualidade e avaliação da qualidade de mudas florestais. In: SEMINÁRIO DE SEMENTES E VIVEIROS FLORESTAIS, 1., 1981, Curitiba. Anais... Curitiba: FUPEF, 1981. p. 59-90.

TAIZ, L.; ZEIGER, E. Plant physiology. Redwood City: The Benjamin/Cummings Publishing Company, 1991. p.249-264.

R. Árvore, Viçosa-MG, v.26, n.4, p.515-523, 2002 